\title{
Botanical Drugs, Synergy, and Network Pharmacology: Forth and Back to Intelligent Mixtures
}

Author

Affiliation
Jürg Gertsch

Institute of Biochemistry and Molecular Medicine, University of Bern, Bern, Switzerland

\author{
Key words \\ - polypharmacology \\ - network pharmacology \\ - drug discovery \\ - synergism \\ - synergy \\ - herbal medicine \\ - phytotherapy \\ - pharmacodynamics \\ mixtures \\ - evolution
}

\section{Abstract \\ $\nabla$}

For centuries the science of pharmacognosy has dominated rational drug development until it was gradually substituted by target-based drug discovery in the last fifty years. Pharmacognosy stems from the different systems of traditional herbal medicine and its "reverse pharmacology" approach has led to the discovery of numerous pharmacologically active molecules and drug leads for humankind. But do botanical drugs also provide effective mixtures? Nature has evolved distinct strategies to modulate biological processes, either by selectively targeting biological macromolecules or by creating molecular promiscuity or polypharmacology (one molecule binds to different targets). Widely claimed to be superior

Synergistic functional effects of various kinds have been a necessary, if not sufficient, requisite for the evolution of cooperation and complexity at all levels of biological organization.

Peter A. Corning (Nature's Magic: Synergy in

Evolution and the Fate of Humankind, 2003)

revised February 9, 201

accepted February 14, 2011

Bibliography

Dol http://dx.doi.org/

10.1055/s-0030-1270904

Published online March 16,

2011

Planta Med 2011; 77:

1086-1098 @ Georg Thieme

Verlag KG Stuttgart - New York .

ISSN 0032-0943

Correspondence

Prof. Dr. Jürg Gertsch

Institute of Biochemistry

and Molecular Medicine

University of Bern

Bühlstrasse 28

3012 Bern

Switzerland

Phone: +41316314124

Fax: +41316313737

gertsch@mci.unibe.ch

\section{Introduction}

$\nabla$

The dominant paradigm in drug discovery is the concept of designing maximally selective ligands to act on individual drug targets [1,2]. This concept is not man-made but indirectly copied from nature. Selective pharmacological principles that occur obviously by chance in certain plants and animals have raised the awareness of the existence of such ligands. Examples include the highly-specific microtubule-interacting agents from Colchicum autumnale L., Catharanthus roseus (L.) G. Don., and Taxus brevifolia Nutt. [3, $4]$, or the potent cardioactive glycosides from Digitalis spp., Strophanthus spp., Convallaria ma- over monosubstances, mixtures of bioactive compounds in botanical drugs allegedly exert synergistic therapeutic effects. Despite evolutionary clues to molecular synergism in nature, sound experimental data are still widely lacking to support this assumption. In this short review, the emerging concept of network pharmacology is highlighted, and the importance of studying ligandtarget networks for botanical drugs is emphasized. Furthermore, problems associated with studying mixtures of molecules with distinctly different pharmacodynamic properties are addressed. It is concluded that a better understanding of the polypharmacology and potential network pharmacology of botanical drugs is fundamental in the ongoing rationalization of phytotherapy. jalis L., and Antiaris toxicaria (Pers.) Lesch., which target the $\mathrm{Na}^{+} / \mathrm{K}^{+}$-ATPase, one of the most abundant membrane proteins in nature. Cardioactive glycosides increase intracellular $\left[\mathrm{Na}^{+}\right]$and a $\mathrm{Ca}^{2+}$ gain via the $\mathrm{Na}^{+}-\mathrm{Ca}^{2+}$ exchanger (NCX) [5] causing positive inotropic effects at low doses and other pharmacological effects at higher doses [6]. Likewise, we may mention that the highly potent and relatively selective agents are the major analgesic and/or psychoactive phytochemicals from Papaver somniferum L., Erythroxylon coca Lam., Psilocybe spp., and Cannabis sativa L. [7], as well as the highly effective blockers of voltage-gated ion channels from pufferfish Takifugu spp. [8]. In recognition of the potency of single substances, the physician Ernst Anton Nicolai already in 1788 criticized the popular view that the more ingredients a drug had the better it was [9]. He questioned the unnecessary complexity of the opiate containing alexipharmakon mithridatium, a form of theriac, and warned about potential antagonisms, suggesting simple recipes in favor of artificially compiled mixtures. Mithridatium typically 
contained opium, myrrh, saffron, ginger, cinnamon, and castor oil, along with some forty other ingredients $[10,11]$. Patients would use theriacs as a preventative against any kind of poisoning and eventually against just about anything. Nicolai, like most physicians today, believed in the advantage of specific monosubstances, and long before the discovery of metabolizing enzymes raised concerns about adverse drug interactions. Doubts about the efficacy of these complex panaceas arose in the mid- $18^{\text {th }}$ century and concerns of the adverse nature of interactions between the numerous ingredients surfaced in Heberden's treatise of 1745 [12]. In Western medicine, the emerging molecular pharmacology or biomedicine soon became the cornerstone of drug discovery. Paul Ehrlich is often quoted for his postulate of creating "magic bullets" for the use in the fight against human diseases. His work has inspired generations of scientists to devise powerful molecular therapeutics with clearly defined targets, ranging from microorganisms to macromolecules [13]. Subsequent to the isolation of the first bioactive natural products and the generation of the first synthetic therapeutic agents, the scientific concept of maximally selective and highly potent ligands was continuously developed. This was primarily based on the increasing knowledge about the molecular nature of drug action and the structure elucidation of macromolecules over the last 50 years [14]. Several bioactive natural products were also instrumental in the elucidation of physiological targets, and biologically active small molecules have long proven useful in the exploration of cell biology [15]. For example, in the early 20th century Otto Löwi discovered acetylcholine and its receptors [16]. He classified the receptors according to ligand specificity as muscarinic and nicotinic, respectively, because the parasympathomimetic natural products muscarine from Amanita muscaria (L. ex FR) Lam. and nicotine from Nicotiana tabacum L. rather selectively target these structurally distinct acetylcholine receptors. Until recently, the paradigm of potent and selective drugs remained unchallenged in the context of drug discovery and development $[2,17]$.

There are numerous examples where the classic medicinal chemistry approach has led to the development of successful drugs with as yet unchallenged target-selectivity, and only some selected examples are provided here. These include the microtubule-targeting anticancer agents currently used in the clinic, which show maximal selectivity and potency in targeting microtubule dynamics in combination with favorable pharmacodynamics properties, as exemplified by the phytochemical taxol and its synthetic analogue taxotere (vide supra) and ixabepilon, an analogue of the microbial natural product epothilone B [18]. Or diazepam (valium), a potent anxiolytic and sleep-inducing benzodiazepine which selectively and potently targets $\mathrm{GABA}_{\mathrm{A}}$ receptors in brain synapses (although it also weakly binds to mitochondrial benzodiazepine receptor [MBR]) [19]. Regarding the discovery of diazepam, Leo Sternbach commented that it was surprising that a spontaneously occurring lactam degradation product of chlordiazepoxide yielded a compound that was more active than this very first benzodiazepine [20]. Thus, medicinal chemistry and serendipity enabled the optimization of this drug lead. Other examples include the selective proton-pump inhibitors (PPIs) of the gastric $\mathrm{H}+/ \mathrm{K}+-$ ATPase like $(R)$-lansoprazole, which prevents the stomach from producing gastric acid [21], and the anticancer agent gefitinib (Iressa ${ }^{\circledR}$ ), the first selective inhibitor of epidermal growth factor receptor's (EGFR) tyrosine kinase domain [22]. The latter was synthesized in a medicinal chemistry initiative at AstraZeneca.
Rather intriguingly, based on this paradigm of selective and highly potent drug actions, during the last 20 years relatively few drugs have reached the market due to high attrition rates [23]. As appropriately mused by Morrow et al. [23], despite the dramatic increase of global spending on drug discovery and development, the approval rate for new drugs is declining, due chiefly to toxicity and undesirable side effects. In fact, lack of efficacy and toxicity are the two main causes for attrition in drug development, accounting for $60 \%$ of the failures [24]. There are numerous cases where highly selective and potent drug candidates turned out to be toxic or ineffective in late-stage preclinical studies. For instance, highly selective kinase inhibitors were developed in vitro to treat certain forms of cancer, but turned out to be toxic or ineffective in vivo [25]. As a target class, kinases have received considerable attention over the last 20 years. There are now 8 kinase inhibitors on the market, approved for treat different types of cancer, with many more in clinical development. All of the approved compounds inhibit more than one tyrosine kinase, although they maintain certain selectivity over the serine/ threonine and phosphoinositide kinase classes. This multiple target activity has proven advantageous in an oncology setting [26]. The well-publicized market withdrawal of Vioxx (rofecoxib), which is a potent and selective COX-2 inhibitor, stands for a series of high-profile pharmaceutical products that were taken off the market due to safety reasons. Was Ehrlichs drug paradigm overstressed in drug research and development, and was the excessive off-target profiling, made possible through new assay technologies, counterproductive in the search for efficacious drugs? We may assume that polypharmacology is positively associated with drug actions. Indeed, most of the known successful drugs that are on the market appear to act via modulation of multiple proteins rather than single targets. In drug discovery, lead profiling to reduce potential off-target effects at target families associated with toxicity or adverse effects helped to make drugs safer [27]. Nevertheless, most therapeutically effective central nervous system (CNS) drugs appear to interact with more than one relevant protein target. This is also true for most other drug families. As pointed out by Brötz-Oesterhelt and Brunner [28], all antibiotics that have been successfully employed for decades as monotherapeutics in the treatment of bacterial infections rely on mechanisms of bacterial growth inhibition which are by far more complex than inhibition of a single enzyme. Drug-target interactions with antibiotics involve the modulation of whole networks rather than single targets [29]. It is tempting to speculate that nature itself has evolved the concept of so-called "dirty" or promiscuous agents to achieve pharmacological potency and plasticity by polypharmacology (vide infra).

The question raised here is whether bioactive mixtures of promiscuous natural products are conceptually better than targetselective monosubstances $[30,31]$ and whether phytotherapy, making use of natural mixtures of phytochemicals, is leading the way. In this short note, I take a look at the different aspects of drug mixtures and their potential as medicines. To that aim, the emerging concepts of polypharmacology and network pharmacology will be discussed in the context of ecological chemistry and the pharmacology of botanical drugs. In particular, the inherent complexity and the challenges that are encountered in this line of research will be highlighted. Needless to say that the topic is large and I shall bring up only a few selected examples although many more could be provided. 
On the Culture of Mixing, Looking for Synergies, and the Dangers of Drug Interactions

$\nabla$

A hallmark of traditional phytotherapy is to make use of plant extracts to fabricate rather complex combinations. Many medicinal plants are now also registered and marketed as molecular mixtures under the label of botanical drugs, and even single extracts are mixtures [30]. From a historical point of view, the mixing of ingredients may well reflect the cultural diversity and ethnic ingenuity, or an ancient longing to find a panacea (i.e., the perfect mixture), or simply the incapacity of isolating the active principle. Indeed, drug recipes of plant mixtures together with magic formulae are already found in the ancient Egyptian medicinal book referred to as Papyrus Ebers, written in 1500 BC [32]. The 12th century manuscript Antidotarium Nicolai is considered as the first general dispensatory, and it was the first guide for composed medicines [33]. In China, formulations of botanical mixtures have continuously evolved over the last thousand years and more than 100000 formulae are currently documented [34, 35]. Even the contemporary Western pharmacopoeias (e.g., Phar. Eur.) list medicinal plant combinations that are as ancient as Dioscurides De Materia Medica [36]. The same picture is seen in traditional pharmacopoeias worldwide (vide infra). The obvious question here is whether such drug mixtures have been designed based on empirical (i.e., scientific) principles [35] or whether they merely reflect upon the (irrational or a priori) intuitions of the practitioners and traditions $[37,38]$, or both? Patwardhan et al. [39] argue that medicinal plants have been validated over thousands of years and that this makes them outstanding (also in a pharmacological context). The emerging picture is that approximately $10-30 \%$ of all higher plants known are used in a therapeutic context and are regarded as medicinal [40-43], depending on the region and cultural diversity (this may not be true for poorly inhabited habitats like tropical rain forests). Is it possible that two out of ten plants possess medicinal properties? If this is the case, what is the contribution of the mixtures of phytochemicals? It is not my intention to question the empirical nature of ethnopharmacology $[39,44]$, but I intend to partially deconstruct the pharmacology part. This is necessary to provide a basis on which to discuss the role of molecular pharmacology. One should not forget that it is a long way to prove that botanical drugs are pharmacologically effective and that mixtures are better than monosubstances. Since therapeutic effectiveness also includes nonmolecular aspects such as the placebo effect (meaning response) $[45,46]$, the focus in this note is explicitly on the molecular pharmacology part. Reverse pharmacology, a term originally coined to describe the de-orphanization of $G$ protein coupled receptors (GPCRs) [47] but here used to describe the process of uncovering the mode of action of botanical drugs [39], has led to the elucidation and isolation of highly potent constituents in traditional medicines or poisons (morphine, cocaine, $\Delta^{9}$-THC, digitoxin, lysergic acid, and aconitine, etc.). Such molecules were typically used as lead structures for drug discovery or chemical biology $[48,49]$. Thus, in most cases only defined constituents in the given mixtures proved to be relevant for the pharmacological activity. In the last decades the discovery of highly potent leads from medicinal plants has declined despite the marked increase in scientific studies on this topic and the discovery of numerous promising natural leads from microbial or marine sources [50, 51]. This has fostered or led to the notion that in phytotherapy, most probably, the mixture makes the medicine. On the other hand, the history of botanical drugs worldwide (traditional de materia medica) becomes a more frequent issue in contemporary pharmacology and the scope of drug discovery in traditional formulations is further expanding [35,52]. Ethnopharmacologists correctly tend to believe that during cultural evolution such botanical drug formulations may have been developed empirically $[35,44,53-55]$. However, it is important to remember that most traditional pharmacopoeias are not based on molecular concepts but contain predominant metaphysical elements and believes (e.g., doctrine of signatures, incorporation of spiritual healing, magic, etc.). Thus, the history of medicinal plants may trick the naïve molecular researcher because from an emic point of view, mixtures and admixtures mean more than molecular pharmacology. During ethnopharmacological fieldwork among the Yanomami Amerindians in the Venezuelan Amazon, I observed that the hunting poison curare (mamokori) could contain up to 10 distinct botanical ingredients, depending on regional differences and local recipes, and some admixtures also contained highly toxic principles [56]. Irrespective of the admixtures, the plants that were considered to be essential for the toxic action were species of the tubocurarine containing plant genus Strychnos (Loganiaceae), all referred to as momokori. However, the admixtures could improve the poison (overall effectiveness) providing holistic qualities even outside the scope of pharmacology; e.g., they made the hunter more apt and the animal imprudent. Variations in recipes among villages were also found for the hallucinogenic snuff yopo, despite the fact that the bioactive principles are tryptamines, i.e., dimethyltriptamine (DMT), from the seeds of the Fabaceae Anandenanthera peregrina (L.) Spreng. Without a controlled experimental analysis during fieldwork, it was impossible to find out whether the addition of admixtures actually improved the effectiveness of the main plant (i.e., Strychnos sp.). The same Yanomami groups in the remote rain forests suffered from bacterial eye infections and did not make an association between infection and disease transmission, just like people in the West prior to Joseph Lister and the discovery of general antiseptics. Thus, while they did not make use of antimicrobial agents from plants (e.g., antiseptic resins), poisons and snuff drugs were highly evolved principles in the traditional Yanomami society and fundamental for hunting and spiritual healing, respectively. Irrespective of the fact that empirical observations can either be reliable or misleading, traditional pharmacopoeias surely are always more than molecular pharmacology. However, the concept of mixing plants to make a more potent poison or medicine is ancient and is very popular in the diverse forms of traditional phytotherapy, including the schools of Traditional Chinese Medicine (TCM), Ayurveda, and the numerous ethnic pharmacopoeias. Therefore, the apparently conserved ethnomedical trait of using plant mixtures to cure should not be ignored in contemporary pharmacology, but considered more carefully. Even in countries where monosubstances are easily available, botanical drug mixtures are prescribed frequently. In Japan, more than $50 \%$ of allopathic doctors prescribe traditional medicines (e.g., Kampo) for their patients. In the UK, between $7 \%$ and $48 \%$ of cancer patients report taking botanical drugs after diagnosis [57]. In the US the number of visits to providers of Complementary Alternative Medicine in the last decades has exceeded the number of visits to all primary care physicians [5759]. According to the WHO, in some Asian and African countries, $80 \%$ of the population depends on traditional medicine for primary health care [60]. TCM, Ayurveda, and Tibetan botanical drugs are booming in the Western world, and the development and commercialization of botanical drug mixtures in allopathic 
medicine is continuously increasing. In particular, TCM products, which are usually mixtures of plants and other natural agents, are becoming increasingly popular [61]. Kong et al. speak of a paradigm shift (probably meaning a backward shift) from finding single agents to combining them to generate new remedies [35]. No one would contradict that in order to appreciate such mixtures as potentially interesting and therapeutically relevant, we need to deconstruct their underlying pharmacology. Endeavors in this direction have been widely reported. To provide an example, PHY906, a four-herb TCM formulation with a history of more than 1500 years of human use, is currently being developed as rational phytopharmakon by the Chinese company Phytoceutica, Inc. [62]. Each of PHY906's four component plant species possess a distinct pharmacological profile, including anticancer and antiviral activity, hematological and immunological stimulation, analgesic activity, liver protection, and appetite improvement [62]. While for Western pharmacologists this heterogeneity may be confusing, Asian practitioners do not see a problem in the polyvalent nature of such medicines. Traditionally, PHY906 has been used to treat diarrhea, abdominal spasms, fever, headache, vomiting, nausea, extreme thirst, and subcardial distention. Although a phase I/IIA double-blind, randomized, placebo-controlled, cross-over, dose escalation clinical study of PHY906 to reduce toxicity of irinotecan-based chemotherapy with advanced colorectal cancer has been carried out successfully, this botanical drug has not yet obtained FDA approval. Thus, future clinical studies will show whether PHY906 safely counteracts the toxicity of irinotecan via the multiple, apparently synergistic anti-inflammatory mechanisms recently reported [63]. The Tibetan botanical drug mixture Padma 28 has been shown to be clinically superior over placebo to treat intermittent claudication [64]. The herbal four-plant preparation Ze185 showed to be an efficacious and safe short-term treatment in patients with somatoform disorders, superior over placebo [65]. However, to date there is no clear insights as to how Padma 28 and Ze185 might exert such therapeutic effects and whether all constituents are necessary for therapeutic efficacy. These examples show that contemporary evidence-based phytotherapy continues to employ botanical drugs to achieve superior effects over monosubstances, taking the risk of complexity criticized by Nicolai more than 200 years ago. Unfortunately, so far there is relatively little sound data (including clinical data) that would provide a strong scientific basis to justify the mixing of plant extracts to improve pharmacological efficacy. But they do exist. A classic example is the hallucinogenic Amazonian plant mixture ayahuasca first reviewed in Schultes $[66,67]$. By mixing plant extracts that contain both inhibitors of the enzyme monoamine oxidase (MAO) and psychoactive tryptamines, indigenous practitioners in the remote past, by error and trial or serendipity, developed the first formulation of orally available psychoactive tryptamines [67]. This is an outstanding example of pharmacological synergy between two classes of compounds that target different proteins. There are many other recent reports on actual and putative pharmacological synergies between plant mixtures and/or single phytochemicals [68-83], but in many cases the experimental proof and in particular the clinical corroboration remain insufficient. Rational drug combinations are known in the clinic and have first been pointed out by Berenbaum in the 1980s [84]. A recent example is the Chinese antimalarial plant Artemisia annua L. Although the pharmacological lead compound artemisinin was isolated and developed clinically, the use of the drug as a monotherapy is explicitly discouraged by the WHO as there have been signs that malarial parasites are developing resistance to the drug. Combination therapies that include artemisinin are the preferred treatment for malaria, and are both effective and well tolerated in patients [85]. In conventional Western medicine different drugs are frequently administered at the same time, thus causing wanted or unwanted mixtures of pharmacologically active compounds [84]. Wanted effects include drug combinations in pain management [86,87] or the coadministration of P-glycoprotein (P-gp) inhibitors (e.g., Zosuquidar trihydochloride or Tariquidar [XR9576]) with anticancer agents that tend to be substrates for this $\mathrm{ABC}$ transporter, thus preventing chemoresistance [88]. Multitarget therapy is used in the treatment of AIDS and infectious diseases. Penicillin-type antibiotics are coadministered with clavulanic acid to prevent bacterial resistance [89]. The mixing of drugs seems to be a logical consequence of a linear pharmacological way of thinking.

At the level of bioavailability, there are numerous studies showing that by combining compound mixtures the pharmacokinetics of certain bioactive natural products can be improved [90-92]. For example, piperin, the major alkaloid found in black pepper (Piper nigrum L.) has been shown to improve the oral bioavailability of otherwise poorly absorbable compounds [93]. One such example is the combination of piperin and curcumin, leading to an improved bioavailability of curcumin, an anti-inflammatory and anticancer phytochemical from turmeric [94]. The important issue of bioavailability will be discussed below.

Drug combinations can also be dangerous due to unwanted interactions. A 2007 report by the US Centers for Disease Control and Prevention (CDC) found that deaths from accidental drug interactions rose 68 percent between 1999 and 2004, continuing a steady climb since the early 1990s. Unintentional drug poisonings accounted for nearly 20000 deaths in 2004, making the problem the second-leading cause of accidental death in the United States, after automobile accidents [95]. At the level of pharmacodynamics, drug interactions as found in plant mixtures can also be detrimental [96]. A now classic and widely cited example is the induction of CYP450 enzymes and P-gp by the bioactive lead compound hyperforin in St. John's wort (Hypericum perforatum L.), which is used to treat mild forms of depression [97]. Moreover, several botanical drugs contain toxic or even lethal principles, which need to be removed or avoided, such as, e.g., pyrolozidin alkaloids and aristolochic acid [98-101]. Overall, it would probably be too simple to assume that plant mixtures are per se advantageous over monosubstances, unless there would be an evolutionary explanation. And there is always an evolutionary explanation. In the next section we will consider the concept of synergism in biological systems, looking for evolutionary clues to the superiority of compound mixtures.

\section{Synergism, an Evolutionary Approach \\ $\nabla$}

Nothing in biology makes sense except in the light of evolution. Theodosius Dobzhansky (1973)

According to the Mosby's Medical Dictionary (2008), pharmacological synergy or synergism is a joint action of two (or more) molecules (drugs) in such a manner that one enhances the action of the other to produce an effect greater than that which may be obtained with either one of the molecules in equivalent quantity or produce effects that could not be obtained with any safe quantity of either molecule, or both. Potentiation, another term used 
in receptor pharmacology, is a synergistic action in which the effect of two drugs given simultaneously is greater than the sum of the effects of each drug given separately. Thus, pharmacological synergy is reflected by a super-additive $\left(a_{n+m} \geq a_{n}+a_{m} / f[x+y] \geq f\right.$ $[\mathrm{x}]+f[\mathrm{y}])$ or super-multiplicative $\left(\mathrm{a}_{\mathrm{n}} \cdot \mathrm{m} \geq \mathrm{a}_{\mathrm{n}} \cdot \mathrm{a}_{\mathrm{m}} / f[\mathrm{x} \cdot \mathrm{y}] \geq f[\mathrm{x}] \cdot f[\mathrm{y}]\right)$ physiological effect by two or more molecules acting together at defined concentrations. Berenbaum was among the first to define pharmacological synergy and carried out pioneering work in the elucidation of molecular potentiation between two drugs and drug interactions $[84,102,103]$. He introduced and developed the "isobole method" which is a valuable tool also in the study of phytopharmaceuticals [30]. Advocates of botanical drugs have always been looking for synergies and were never tired of stressing the point that in phytotherapy the mixture makes the drug. But is the chemical composition of botanical drugs ever questioned, and can we be sure that nature provides us with the ideal mixtures? Clearly, plants do not produce secondary metabolites to benefit mammals but produce them to potentially address the diverse ecological pressures, such as microbial or predator attack. Plants often respond to a stressor by increasing the biosynthesis of different classes of molecules rather than just an individual secondary metabolite $[104,105]$. This may be a complex reaction to a specific predator attack [106]. Or mixtures may simply affect the solubility and distribution of the potentially active constituents. In light of absorption and distribution (how to get the poison into the predator) mixtures can be favorable. For example, the ichthytoxic lignans justicidin B and piscatorin in the Amazonian fish poison plant Phyllanthus piscatorum L. are readily soluble in water when administered in the plant extract but almost water insoluble when purified [107].

In an outstanding article by Corning (1998) "The Synergism Hypothesis: On the Concept of Synergy and It's Role in the Evolution of Complex Systems" [108] the author argues that synergy can provide universal functional advantages in the phenomenal world, thus providing an evolutionary gain at multiple levels. If we observe nature, bioactive compounds are very rarely produced alone, but almost always occur in mixtures with other potentially bioactive secondary metabolites. Moreover, many physiological mediators (i.e., amines, fatty acid metabolites, steroids, etc.) act by simultaneously targeting different sites. Biochemical processes often involve multiple signaling molecules that drive the biological response into one or the other direction. It is tempting to reason that nature produces groups of potentially synergistic effectors to increase the chance for success. In his fundamental paper on synergy, Berenbaum provided numerous examples of biological synergies as they might occur in physiological processes [84]. In the context of "chemical warfare" or biochemical communication, it may thus be highly advantageous (at the level of cost-benefit) for an organism to produce mixtures of molecules or molecules that are privileged scaffolds (i.e., molecules which have an intrinsic tendency towards polypharmacology, i.e., low specificity). Maybe this is the reason why polyphenolic natural products are ubiquitous in plants (positive selection of biosynthetic gene clusters) but easily metabolized and detoxified by mammals (through adaptation) [109]. From such a point of view, polyphenolic natural products which are found in numerous plants and easily undergo molecular interactions via hydrogen-bonding might favor synergies. Polyphenolics frequently target proteins in vitro and are a ubiquitous and well-evolved class of natural products. Moreover, numerous plant polyphenols have been shown to act as antioxidative agents in vitro, targeting reactive oxygen species which are potentially involved in patho- physiological processes [110]. Zhang et al. [111] questioned that polyphenols (particularly flavonoids) have evolved for scavenging free radicals. Their opposing findings, based on evolutionary reasoning, provide new clues to understanding why the strong in vitro antioxidant activities of polyphenols cannot be translated into in vivo effects, but may be related to protein interactions [111]. Molecular interactions produced by organisms could be a means to fitness. From such a theoretical point of view, synergies in botanical drugs would make absolute sense. We know that one organism can have a negative effect on another (e.g., the predator on prey), and this concept could be easily transferred to the molecular level $[112,113]$. However, it is often forgotten that cooperative effects are far more common in nature (e.g., cells are self-assembling synergistic combinations of molecules!). The probability that a mixture from the same source evolved to deter or attract another organism does more of the same (in a superadditive manner) than to exert a mixed-type of response seems to be rather high. Berenbaum [84] stressed the synergic action of toxicological agents, but synergies are frequent in all contexts of ecology [114]. For instance, symbiosis between fungi and plants is essential for survival in most species, eukaryotic cells are forms of symbiosis, and humans cannot survive without bacterial symbionts in the gastrointestinal tract. Chemical signals are used widely between plants and insects in symbiosis. There is a great deal of molecular synergies in soil, an ecologically crowded place, involving different kinds of organisms [115, 116]. At all levels of nature, advantages frequently arise from cooperation between organisms and this should also be true at the molecular level and could be exploited in drug action.

The teleological question why plants and other organisms produce secondary metabolites has been the subject of debate for many decades. As discussed by Firn and Jones [112,117], there are two extreme opinions. Some argue that most secondary metabolites play no role in increasing the fitness of an organism. The opposite view is that every secondary metabolite is made because it possesses (or did possess at some stage in evolution) a biological activity that endows the producer with increased fitness. According to Firn and Jones [117], these opposing views can be reconciled by recognizing that, because of the principles governing molecular interactions, potent biological activity is a rare property for any molecule to possess. In fact, there are relatively few pharmacologically highly potent secondary metabolites known (e.g., defined by low nM binding to target), and they may represent less than $1 \%$ of the total of all natural products. There are more than 5000 distinct natural product scaffolds (chemical skeleta) [118], but less than 100 have so far inspired the development of biomedical monotherapies. The same ratio could be expected in the context of ecological chemistry (number of compounds that increase fitness of the host). Consequently, in order for an organism to evolve a biologically active molecule, many chemical structures would have to be generated (vide infra), most of which will possess no biological activity at all [113]. But this would be very inefficient, and we should not forget that evolution always works with synergies. Therefore, the action of combinating synergistic molecules should be seen as an evolutionary principle. If we assume that phytochemical mixtures exert synergistic biological effects, more effects per scaffold would be possible ( Fig. 1). In theory, three apparently ineffective scaffolds combined could yield one effect. Maybe a deeper analysis of the scaffold frequencies found in medicinal plants could shed light on pharmacologically important classes of phytochemicals. It is certainly not a coincidence that alkaloids figure as the pri- 


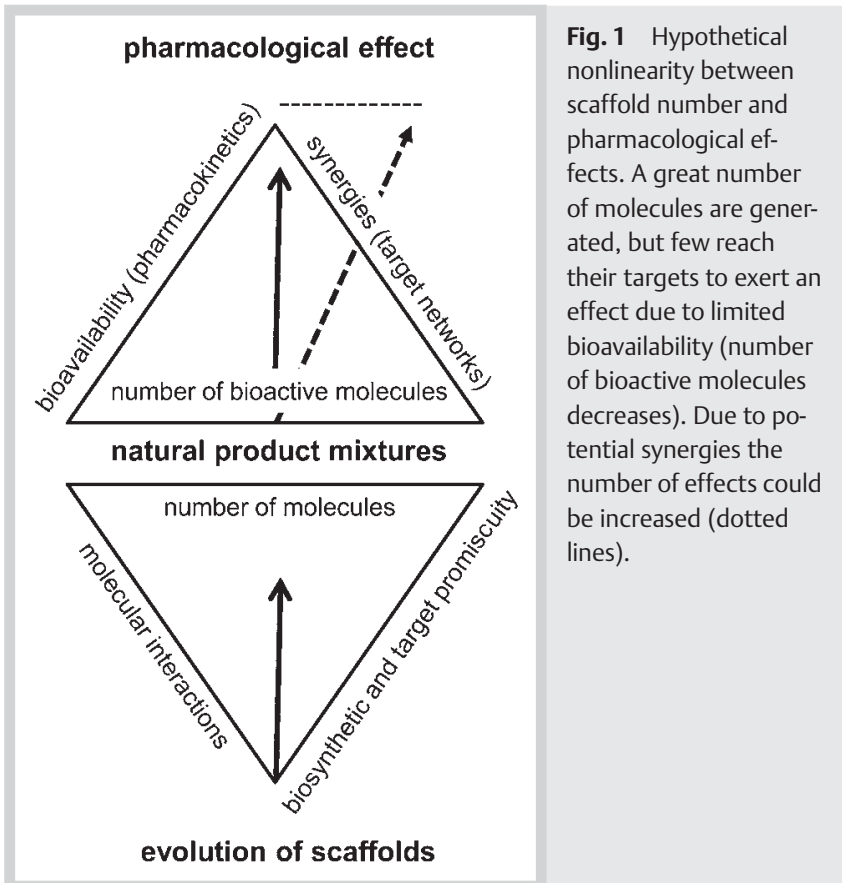

mary source for centrally active agents from plants and that, e.g., the indole scaffold was very successful [119].

In a commentary by Fischbach and Clardy, it was pointed out that secondary metabolic pathways, which are turned on in response to specific cues and make natural products, typically make a variety of products $[120,121]$. Some pathways make only one or two products, and some make more than 100 . Thus, primary metabolic pathways are target-oriented, whereas secondary pathways are diversity-oriented. Biosynthetic molecular promiscuity, just like polypharmacology, seems to be a hallmark of molecular evolution. In light of the cost-benefit aspect of producing secondary metabolites it should be particularly beneficial for a plant to produce mixtures of small molecules made of simple and ubiquitous building blocks that easily diffuse to reach a maximal number of potential targets. Such molecules could be small isoprenoids, such as the volatile hemiterpenes, monoterpenes, and sesquiterpenes found in plant essential oils. Along the same line, convergent biosynthetic evolution (two different organisms hitting upon the same overall strategy to make the same collection of small molecules using unrelated gene products) is more frequently found in terpenes (e.g., gibberellins [120]). Overall, a high degree of pharmacological synergism should be expected in essential oils, which are prototypical mixtures of secondary metabolites. Unfortunately, despite promising recent findings [122124], relatively little research is dedicated to the molecular pharmacology of volatiles, probably because these compounds do not fit in the current concept of drug-like molecules. The terpene combination medicine Rowatinex consisting of essential oil components was recently shown to be effective in urolithiasis and significantly improved stone clearance [125]. Volatile essential oil components are promising agents to treat pain and inflammation [126,127]. Thus, mono- and sesquiterpene scaffolds appear to hold great promise for future drug discovery. Volatiles can be highly variable within a taxon, which again reflects environmental adaptations and an ongoing molecular evolution $[128,129]$. And this molecular arsenal may be used by all forms of life. For example, the dynamic evolution of polyketide-derived pyrones was shown to be present in all kingdoms of life [130]. A theory of the evolution of secondary metabolites needs to take into account dynamic responses to environmental changes [131]. From an evolutionary point of view, networks of synergic molecules could greatly enhance the chance for fitness. It is therefore conceivable that using complex mixtures rather than monosubstances is closer to a trial and error-type of selection. If you do not know what to use it may be a good strategy to use a mixture, in case there is at least one principle that helps. Furthermore, there is also a fair chance that any kind of synergy will be picked up (see case below on Mexican physician). It would not be surprising if nature itself would show the way towards novel treatments regimes involving synergistic pharmacological effects for complex multifactorial diseases such as cancer, cardiovascular and autoimmune diseases, or type 2 diabetes.

A literature survey on pharmacological synergy indicates that studies on botanical drugs are well represented in this area of research (summarized in [30]). A search in espacenet (www.ep. espacenet.com) reveals that patent applications on apparently synergistic botanical formulations in Asia are increasing almost exponentially. Thus, the concept of synergism is also a selling argument and benefits homo economicus. Although the term synergy (or synergism as the underlying concept) is used frequently, the terminology remains somewhat unclear in phytotherapy. While there are numerous reports on synergies found in vitro, relatively few sound data are available from clinical studies. The synergies that can be measured in vitro may not occur at a systemic level (see discussion below on pharmacodynamics). As previously discussed by Williamson, 2001 [132], Ulrich-Merzenich et al., 2009 [133], Verpoorte et al., 2009 [55], Wagner, 2009 [72], and more recently by Koch and Efferth [91], synergistic combination therapies as found in phytotherapies are also being developed for multifactorial diseases in conventional medicine. Examples of pharmacological synergies are increasingly widespread in the experimental literature. While biomedicine usually defines synergism at the level of molecular mechanisms and well-designed clinical studies, in phytotherapy the evidence often remains anecdotal. Some notable exceptions have been reported [30], but from a total of an estimated 10000 medicinal plants less than $1 \%$ has been studied in such trials. I think that there is a great potential in this line of research also to get insight into the way biological systems work. In fact, pharmacological synergy classifications have proved powerful in dissecting the modularity and connectivity of the underlying biological networks [134, 135]. In order to achieve this level of depth in pharmacognosy, the molecular mechanisms need to be understood first. At present, much of the discussion remains philosophical.

\section{From Polypharmacology to Network Pharmacology}

$\nabla$

Although healing may be magic it is hard to believe that there is a therapeutic effect without a molecular mechanism of action.

Botanical mixtures that contain hundreds of potentially bioactive natural products often do not reveal the desired molecular mechanisms of action. A major bottleneck in botanical drug research is the identification of the molecular targets of all bioavailable compounds within the extract (i.e., the overall mode of action). In many cases no feasible mode of action can be elucidated by using conventional biochemical methodologies [39]. Nevertheless, such botanical drugs may still be effective in vivo beyond their meaning response (i.e., placebo effect). The question arises how 
such complex mixtures might work if not by potently inhibiting a particular protein target. It is possible that certain natural products in botanical drugs weakly target different proteins within the same signaling network ( $\bullet$ Fig. 2 ), thus shutting down the whole process simply by network pharmacology or biochemical synergism. But is it possible that the large number of weakly active plant secondary metabolites in an extract may be enough to exert a pharmacological effect without the presence of a major highly bioactive compound class simply by network pharmacology (i.e., synergy between weakly active compounds)?

The term network pharmacology was coined by Andrew L. Hopkins to stress the point that there are drug-target networks rather than single drug targets [1]. The description of complexity is currently observed in many branches of the Life Sciences. Naturally there are functional relationships (systems biology) in living organisms, and genes and proteins are not isolated in space and time. Wagner [30] states that in most botanical drugs, multi-target effects predominate over other synergistic mechanisms. For drug discovery and pharmacology this means that Paul Ehrlich's concept of the magic bullet may be one of a shotgun. Integrating network biology and polypharmacology holds the promise of expanding the current concepts on druggable targets [2] and may also help to understand the pharmacological action of botanical medicines. However, the rational design of polypharmacology faces considerable challenges in the need for new methods to validate target combinations and optimize multiple structure-activity relationships while maintaining drug-like properties. The latter point is particularly problematic in the development of botanical drugs because they have not been engineered, but simply taken from nature or at best been optimized to some extent (vide infra). Insights in polypharmacology and synergisms are clearly creating the basis of the next paradigm in drug discovery. Depending on the molecular machinery, synergisms can be produced by differential (e.g., allosteric) ligand interactions in one single protein or at the level of downstream effects. If we take into account the gene expression of important signaling molecules, different drugs may act synergistically simply by partially inhibiting different nodes in the biological network that leads to proinflammatory gene expression ( $\mathbf{O}$ Fig. 2). Instead of thinking in terms of individual protein targets, we need to portray ligands as having multiple targets which are connected to other targets or functional networks. Molecules are connected to each other in an ordered manner defined by binding interactions in time and space rather than in a loose hodgepodge. There is good evidence that many anti-inflammatory plant natural products act by binding to and blocking proteins, and this may be the reason why there are so many anti-inflammatory medicinal plants [136]. Along that line, many relatively common plant natural products have been shown to be moderate inhibitors of the key transcription factor NF-kappa B, which regulates the expression of multiple signaling molecules that trigger inflammation and carcinogenesis (reviewed in [137]). Nevertheless, there is no a priori rationale why plants should only produce pharmacologically synergistic and not antagonistic mixtures. Maybe the only rationale would be to assume that in general, and irrespective of their molecular scaffold, secondary metabolites are more likely to inhibit protein functions than to activate them. While they may activate certain membrane receptors, natural products bind to cytoplasmic proteins, thus in the ideal case blocking them. In such a scenario all enzymes causative of the pathophysiology of, e.g., inflammation would be blocked rather than activated, leading to an overall anti-inflammatory effect.

The challenge is to design such a kind of pharmacology. By combining advances in chemoinformatics and structural biology, it might be possible to rationally design the next generation of promiscuous drugs with polypharmacology $[138,139]$. Multidrug combinations are vital in modern medicine [84]. Drug combinations can also be used to probe the relationships between proteins in a network, and progress towards using drug interactions to infer network connectivity has been made in recent years. Not surprisingly, we start to see whole systems rather than individual targets. A study by Lehár et al. [140] takes this effort a step further by developing innovative tools to use the entire data in a drug-drug interaction dose-response surface to give useful information on the networks in which the drug targets are embedded. Such approaches could be envisaged in the study of the pharmacology of botanical drugs. This would help us to answer the question whether plants produce effective mixtures which target such networks. But how could we ever find out about the targets of the characterized secondary metabolites in a botanical drug?

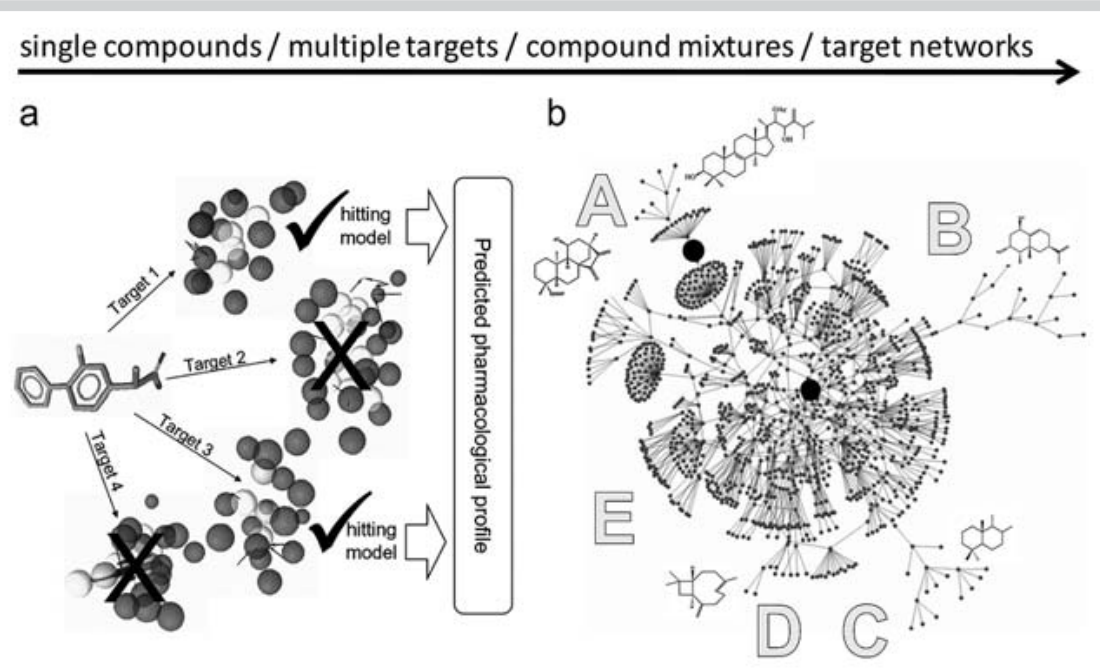

pharmacophore models/physical assays/synergisms/ pharmacodynamics
Fig. 2 Emerging concepts in botanical drug network pharmacology. Natural products may interact with multiple targets (polypharmacology), and this could be assessed by (a) ligand pharmacophore models (image from Rollinger et al. Planta Med 2009; 75: 195-204). b There might be synergistic effects between different natural products (here terpenoids) targeting different receptors in different nodes of the biological space (A-E) leading to blockage of certain pathways (black dots). The elucidation of the effects of bioavailable phytochemicals on cellular networks is a major frontier in botanical drug research. 
For example, the phytopharmaceutical products Iberogast ${ }^{\circledR}$ (functional dyspepsia) and Sinupret ${ }^{\circledR}$ (sinusitis) sold in Europe each consist of a mixture of several plant extracts, harboring hundreds if not thousands of potentially bioactive constituents. Although both botanical drugs have been shown to be therapeutically more effective than placebo in clinical trials [30], it is still not clear how they work. Maybe a combination of a dozen phytochemicals would already be enough to exert the same effect? Network pharmacology may provide the basis to find out. In silico analyses and virtual pharmacology may provide versatile novel tools in the study of botanical medicine polypharmacology. A first groundbreaking example was provided by Rollinger et al. in whose investigation Ruta graveolens constituents were shown to have a series of theoretical and actual pharmacological targets by employing multiple pharmacophore models for in silico screenings [141]. The major virtual hits that were obtained in that way showed a relatively good predictability and were corroborated in biological assays. In this study, the coumarin rutamarin was shown to be a hitherto unrecognized privileged chemical scaffold. Interestingly, $R$. graveolens is one of the most ancient and important medicinal plants in the Mediterranean [142,143], but literally nothing is known about the potential pharmacological action of rutamarin beyond its spasmolytic effects [144].

The role of network pharmacology as typically stressed by practitioners of herbal medicine is now starting to become increasingly more important in contemporary drug discovery and treatment of multifactorial diseases like cancer, cardiovascular and autoimmune diseases $[2,145]$. Nevertheless, rational combination therapies and botanical drugs cannot be directly compared. It is questionable whether a medicinal plant could have evolved secondary metabolites that synergize in their therapeutic effects for one disease area simply by chance. Therefore, in order to appreciate serendipitous beneficial combinations and traditional (empiric) combinations, we first need to differentiate between pharmacologically effective and ineffective botanical drugs. While there are thousands of studies on the effects of phytochemicals in vitro, relatively little is known about the ineffectiveness of phytochemicals.

\section{Pharmacodynamics - Too Complex and Therefore Neglected?

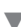

Probably the biggest problem in pharmacological research on botanical drugs is the lack of insight into the pharmacodynamics of potentially bioactive natural products in drug mixtures. In 2008, Wang et al. reported a study in which they dissected the molecular mechanisms of action of a TCM mixture, containing the extracts of three plants, which was developed based on TCM theories in the 1980s to treat promyelocytic leukemia [74]. While the study nicely demonstrates synergy between secondary metabolites (i.e., bioactive extract components) in vitro, it does not address the obviously important issue of pharmacokinetics and pharmacodynamics. The same is true for a study by Gao et al. [146] in which a plausible molecular basis of the synergistic antitumor effect of rhizoma corydali (ezhu) and rhizoma curcumae (yanhusuo) was postulated. Again, the issue of bioavailability was neglected. The phytochemicals highlighted by Wagner [30] to possess the potential to exert synergistic effects with chemotherapeutics, namely curcuminoids and gallocatechins, are poorly bioavailable and rapidly metabolized showing low nM plasma levels (discussed in [147]). It is very important to empha- size time and again that bioactive natural products do not necessarily possess optimal ADME (administration - distribution metabolism - excretion) properties in mammals because the latter have evolved detoxifying mechanisms for many common chemical scaffolds (also found in a vegetable diet) [109]. In light of this, it is highly questionable whether plant extract mixtures should be directly applied to cellular assays as the lack of pharmacokinetic differentiation (e.g., distinct absorption and metabolism) between compounds, as it occurs in vivo, would very likely lead to erroneous conclusions [147]. Fortunately, over the last years, an increasing number of pharmacokinetic studies on bioactive leads in botanical drugs have been carried out [148-157], and fortunately the trend seems to be increasing. If a standardized botanical drug is taken orally, in the best case it is known how the major bioactive constituents are absorbed, distributed, metabolized and excreted (i.e., the pharmacokinetic properties), and frequently only murine data are available. However, in most cases insightful studies on the pharmacokinetics of all constituents are lacking [158]. In the end, to talk about herbal medicine pharmacology requires a knowledge about the actual ligand concentration at a given receptor site. This is fundamental in order to understand the pharmacodynamic behavior of one compound in a physiological context (i.e., ligand + receptor associated vs. free states) and ultimately the mechanism of action. If we have a mixture of several hundred potentially bioactive compounds, we should know what the plasma and tissue concentrations of the individual compounds are and all of the respective receptor interactions ( $K_{\mathrm{d}}$ values) at the given concentration in order to understand how it works. Both maximal concentrations and half times would provide the basis for the feasibility of postulated mechanisms of action from in vitro studies. While all these parameters are commonly known with modern drugs and in the cases where combination therapies are developed, all possible interactions are considered, this is certainly not true for the phytochemicals in botanical drugs. It does not make sense to consider the relevance of a micromolar biological effect in vitro if only nanomolar concentrations of the natural product are found in plasma and tissues. Such effects are notoriously claimed with poorly bioavailable natural products, but they are misleading and will certainly not help to elucidate the actual mechanisms of action [147]. But how can we tackle the challenging task of studying such complex pharmacology?

To provide a practical example of the challenges: This author knows a Mexican physician who claims to be able to cure different types of cancer by using a mixture of twelve cytotoxic plants [159]. Although obviously no statistical data exist to unambiguously prove his intriguing empirical observations, it would be extremely difficult to study the putative underlying molecular mechanisms of his botanical drug mixture. Assuming that each plant contained one hundred easily detectable compounds (e.g., in an HPLC chromatogram), he would administer a mixture of more than one thousand compounds. To find out which of these compounds are bioavailable, all compounds would have to be analytically identified and determined in blood plasma upon oral administration. To quantify the potentially bioactive compounds by, e.g., LC-MS/MS, for each analyte an internal standard and a corresponding standard curve would have to be established. This is of course a paramount task. In theory, once the bioavailable compounds would be known, the potential synergisms (and antagonisms/dualities) between the individual compounds at the matching plasma concentrations (AUCs) could be studied in vitro. Would one thousand compounds be bioavailable, at the level of 
synergism (e.g., in this particular case with cytotoxicity as the readout), this would result in millions of individual experiments using Berenbaums isobole method [102] if all possible combinations or permutations would be made. Without solid clinical data nobody would engage in such a work-intensive and obviously risky project. Needless to say that plant extracts may show significant intersample variations of phytochemicals. In a sense, all of this is the problem of botanical drugs; an apparently hopeless case. But only when we start to actually carry out pharmacokinetic and metabolomic studies with complex mixtures we will be able to judge whether there are synergies or not. Relatively little funding is spent on pharmacokinetics studies, and ADME issues have largely been ignored in the past. Fortunately, companies manufacturing and selling botanical drugs such as A. Vogel Bioforce AG, Schwabe Pharma AG, Zeller AG, SunTen Phytotech Co. Ltd., and Mediherb, Inc. in the past have funded projects involving issues of bioavailability. Such studies will be crucial and are even more important than in vitro pharmacological investigations as the latter cannot be translated to physiology without knowledge on bioavailability.

\section{The Need to Reengineer Botanical Drugs}

$\nabla$

Every effective drug has a given therapeutic window in which the effective dose is clearly distinguished from the adverse effects that are expected to occur at higher doses. Rather intriguingly, botanical drugs or certain phytochemicals are often claimed to be nontoxic irrespective of the dose administered [99], similar to vegetables, fruits, and certain vitamins. It is hard to conceive how, e.g., the phytochemical and food coloring curcumin (E100), which has hundreds of reported targets and exerts a myriad of potentially beneficial effects, could be safe (nontoxic) if it was bioavailable at the indicated bioactive concentrations. For many years it has been claimed that classical phytotherapy using botanical drug combinations exerts superior efficacy and lesser side effects in comparison with monosubstances [160]. Do we really expect potent therapeutic efficacy of botanical drugs or are the therapeutic effects limited by the poor bioavailability and weak pharmacodynamic effect of many phytochemicals? Or is a high percentage of the empirical effectiveness of botanical drugs due to the meaning response? A possible molecular answer is that, providing the bioavailability of active constituents, botanical drugs exert less side effects because they work with synergies. Thus, they do not need to completely inhibit a target but partially inhibit different targets within a network.

How can we understand such putative synergies? It is questionable whether dissection of extracts and testing of fractions in high-throughput (HTS) screenings will shed light on the potential synergies found with botanical drugs as suggested previously [133] because current HTS technologies do not take into account pharmacodynamics issues and in vitro pharmacology with complex mixtures is likely to produce artifacts [147]. Although the methodology for synergy research recently summarized by Wagner [30] will be suitable to detect molecular synergies in vitro, the situation is much more complex in vivo. In a Nature News Feature, Qiu [34] wrote about the challenges associated with bringing TCM concepts in contact with Western science. In particular, the lack of standardization and the high variability of phytochemicals between samples and microbial contamination [161] of botanical drug formulae remain a challenge. Much of the work currently performed is based on in vitro studies, widely neglecting
ADME issues. However, what we need are thorough in vivo studies addressing the pharmacokinetics and pharmacological effects in vivo (synergisms and antagonisms/dualisms) of phytochemicals found in botanical drugs. Probably, the best way of corroborating the pharmacological efficacy of botanical drugs would be to reengineer the mixtures. By taking apart and reassembling all bioactive constituents, one would be able to find out which natural products contribute to the pharmacodynamics of a given pharmacological effect, either indirectly (i.e., by modulating solubility and bioavailability) or directly (by interacting with particular protein targets). Widely available modern technologies, such as LC-MS/MS, LC-NMR [162-164] and high content screens [165], and other innovative approaches [166-170] should at least in theory allow such endeavors. The simple use of a Caco-2 cell colon epithelial monolayer as a "cellular filter" prior to application of extracts to whole cells would be useful [171], despite the fact that the microflora of the GI would not be taken into account. Many glycosides and higher molecular weight compounds found in plant extracts would not be absorbed or transported and would not interfere with the cellular assay, thus better simulating the physiological situation. In the end, one would find out about the necessary and unnecessary components in a botanical drug. Currently, the situation is that researchers from different disciplines work on natural products including phytochemicals, providing new tools and insights which should eventually enlighten us.

\section{Outlook}

$\nabla$

In the author's opinion, there are two major frontiers in botanical drug research: the role of the meaning response (placebo effect) in empirical and clinical effectiveness, which is not discussed here, and the potential of network pharmacology. Only the rationalization (the process of constructing a logical justification for a decision that was originally arrived at through a different mental process) will shed light on the often obscure nature of the numerous plant-derived drugs with millennial histories. Irrespective of the importance of traditional medicine in developing countries and their growing popularity in the industrialized West $[35,44]$, we need to scientifically address the therapeutic potential of botanical drugs [172]. In particular, the underlying pharmacology should be an issue of major significance. Progress will certainly be made by performing more rigorous studies on the bioavailability of natural products prior to applying these compounds to in vitro assays. Moreover, studies on the pharmacodynamics of natural products are urgently needed to understand pharmacological synergies and the potential network pharmacology of complex mixtures. The reengineering of botanical drugs would make the area of medicinal plant research more scientific (i.e., reproducible) and may even lead to the de novo engineering of more intelligent mixtures than the ones provided by plants. By doing so, we would base our understanding of pharmacological efficacy on measurable molecular parameters. Phytotherapy is often said to be too complex to be understood and therefore achieves a mysterious image that adds to the nimbus of botanical drugs. Nevertheless, advocates of botanical drugs should also accept the possibility that certain medicinal plants may be ineffective despite their tradition. To that end, we need to deconstruct the pharmacology part in ethnopharmacology. The bottom line is that in many cases botanical drugs would not stand the test of randomized double-blind placebo control clinical trials and phar- 
macokinetic and pharmacodynamic modeling. The history of medicine teaches us that tradition alone cannot warrant quality [38]. If this is too radical, the alternative is to see botanical drugs as "holistic agents" and to interpret effectiveness as a variable of the meaning response. I would not be surprised if plants were entities of evolutionary conserved inducers of a strong meaning response because plants are both food and medicine, and humankind has been using medicinal and magic plants for thousands of years. Interestingly, traditional societies do not even differentiate between magic and medicinal plants, and also animals use plants to cure [173]. But in light of the increasing number of studies on the molecular mechanisms of botanical drugs and their role in drug discovery, it would be hypocritical to abandon the rational approach. To quote the German philosopher Hegel: "What is rational is actual (real), and what is actual (real) is rational". I believe that only the integration of sound ADME studies in polypharmacology and network pharmacology concepts for the research on botanical drugs will provide the necessary tools for the rationalization of phytotherapy. Despite the reality that there are thousands of medicinal plants and botanical drugs, and millions believe in them, it may still be a long way toward a rational phytotherapy. After all, accumulated evidence (tradition) can provide support, validation, and substantiation for the theory that a particular plant is therapeutically effective, but will never prove this theory to be true. In actuality, the only truly conclusive knowledge produced by science results when a notion is falsified. But falsification in medicinal plant research is an unappreciative task and not en vogue in times where cultural heritage and herbal nationalism are on the forefront.

\section{Acknowledgements}

I would like to thank O. Sticher, K.-H. Altmann, M. Hamburger, W. Schühly, M. Leonti, and M. Adams for controversial but stimulating discussions on this topic. Thanks to the criticisms by T.W. Baumann, L. Bohlin, and M. Heinrich, this manuscript could be improved.

\section{References}

1 Hopkins AL. Network pharmacology. Nat Biotechnol 2007; 25: 11101111

2 Hopkins AL. Network pharmacology: the next paradigm in drug discovery. Nat Chem Biol 2008; 4: 682-690

3 Altmann KH, Gertsch J. Anticancer drugs from nature-natural products as a unique source of new microtubule-stabilizing agents. Nat Prod Rep 2007; 24: 327-357

4 Gertsch J, Meier S, Tschopp N, Altmann KH. New tubulin inhibitors from plants: A critical assessment. Chimia 2007; 61: 368-372

5 Hansen 0 . Interaction of cardiac glycosides with $\left(\mathrm{Na}^{+}+\mathrm{K}^{+}\right)$-activated ATPase. A biochemical link to digitalis-induced inotropy. Pharmacol Rev 1984; 36: 143-163

6 Prassas I, Diamandis EP. Novel therapeutic applications of cardiac glycosides. Nat Rev Drug Discov 2008; 7: 926-935

7 Prevatt-Smith KM, Prisinzano TE. New therapeutic potential for psychoactive natural products. Nat Prod Rep 2010; 27: 23-31

8 Fozzard HA, Lipkind GM. The tetrodotoxin binding site is within the outer vestibule of the sodium channel. Mar Drugs 2010; 8: 219-234

9 Nicolai EA. Rezepte und Kurarten mit theoretisch-praktischen Anmerkungen, von D. Ernst Anton Nicolai, Hofrath und Professor zu Jena, Vol. 4. Jena: Cröker; 1788: 567

10 Mann RD. From mithridatium to modern medicine: the management of drug safety. J R Soc Med 1988; 81: 725-728

11 Catellani P, Console R. The rise and fall of mithridatium and theriac in pharmaceutical texts. Pharm Hist (Lond) 2007; 37: 2-9
12 Griffin JP. Venetian treacle and the foundation of medicines regulation. Br J Clin Pharmacol 2004; 58: 317-325

13 Bosch F, Rosich L. The contributions of Paul Ehrlich to pharmacology: a tribute on the occasion of the centenary of his Nobel Prize. Pharmacology 2008; 82: 171-179

14 Triggle DJ. Pharmacological receptors: a century of discovery - and more. Pharm Acta Helv 2000; 74: 79-84

15 Crews $C M$. Targeting the undruggable proteome: the small molecules of my dreams. Chem Biol 2010; 17: 551-555

16 Karczmar AG. The Otto Loewi Lecture. Loewi's discovery and the XXI century. Prog Brain Res 1996; 109: 1-27

17 Hopkins AL, Mason JS, Overington JP. Can we rationally design promiscuous drugs? Curr Opin Struct Biol 2006; 16: 127-136

18 Hunt JT. Discovery of ixabepilone. Mol Cancer Ther. 2009; 8: 275-281

19 Möhler $H$. The rise of a new GABA pharmacology. Neuropharmacology, advance online publication October 28, 2010; doi: 10.1016/j.neuropharm.2010.10.020

20 Sternbach LH. The benzodiazepine story. Prog Drug Res 1978; 22: 229266

21 Andersson T, Weidolf $L$. Stereoselective disposition of proton pump inhibitors. Clin Drug Investig 2008; 28: 263-279

22 Lurje G, Lenz HJ. EGFR signaling and drug discovery. Oncology 2009; 77: 400-410

23 Morrow JK, Tian L, Zhang S. Molecular networks in drug discovery. Crit Rev Biomed Eng 2010; 38: 143-156

24 Chen B, Wild D, Guha R. PubChem as a source of polypharmacology J Chem Inf Model 2009; 49: 2044-2055

25 Yang X, Huang Y, Crowson M, Li J, Maitland ML, Lussier YA. Kinase inhibition-related adverse events predicted from in vitro kinome and clinical trial data. J Biomed Inform 2010; 43: 376-384

26 Knight ZA, Lin H, Shokat KM. Targeting the cancer kinome through polypharmacology. Nat Rev Cancer 2010; 10: 130-137

27 Merino A, Bronowska AK, Jackson DB, Cahill DJ. Drug profiling: knowing where it hits. Drug Discov Today 2010; 15: 749-756

28 Brötz-Oesterhelt $H$, Brunner NA. How many modes of action should an antibiotic have? Curr Opin Pharmacol 2009; 8: 564-573

29 Kohanski MA, Dwyer DJ, Collins JJ. How antibiotics kill bacteria: from targets to networks. Nat Rev Microbiol 2010; 8: 423-435

30 Wagner $H$. Synergy research: approaching a new generation of phytopharmaceuticals. Fitoterapia 2011; 82: 34-37

31 Schmidt BM, Ribnicky DM, Lipsky PE, Raskin I. Revisiting the ancient concept of botanical therapeutics. Nat Chem Biol 2007; 3: 360-366

32 Griffith FL. A medical papyrus from Egypt. Br Med J 1893; 1: 1172 1174

33 Goltz D. Mittelalterliche Pharmazie und Medizin: dargestellt an Geschichte und Inhalt des Antidotarium Nicolai: mit einem Nachdruck der Druckfassung von 1471. Stuttgart: Wissenschaftliche Verlagsgesellschaft; 1976: 136

34 Qiu J. Traditional medicine: a culture in the balance. Nature 2007; 448 : 126-128

35 Kong DX, Li XJ, Zhang HY. Where is the hope for drug discovery? Let history tell the future. Drug Discov Today 2009; 14: 115-119

36 Touwaide A, Pollio A, Aliotta G, Piomelli D, De Santo NG. Medicinal plants for the treatment of urogenital tract pathologies according to Dioscorides' De Materia Medica. Am J Nephrol 1997; 17: 241-247

37 Dowling H. Medicines for man. New York: Knopf; 1973

38 Shapiro AK. The placebo effect in the history of medical treatment: implications for psychiatry. Am J Psychiatry 1959; 116: 298-304

39 Patwardhan B, Vaidya DB, Chorghade M, Joshi SP. Reverse pharmacology and systems approaches for drug discovery and development. Curr Bioact Compd 2008; 4: 201-212

40 Leonti M, Casu L, Sanna F, Bonsignore L. A comparison of medicinal plant use in Sardinia and Sicily-De Materia Medica revisited? J Ethnopharmacol 2009; 121: 255-267

41 Thomas E, Vanderbroek I, Goetghebeur P. The relationship between plant use and plant diversity in the Bolivian Andes, with special reference to medicinal plant use. Hum Ecol 2008; 36: 861-879

42 Moerman DE. Symbols and selectivity: a statistical analysis of native American medical ethnobotany. J Ethnopharmacol 1979; 1: 111-119

43 Moerman DE. An analysis of the food plants and drug plants of native North America. J Ethnopharmacol 1996; 52: 1-22

44 De Vos P. European materia medica in historical texts: longevity of a tradition and implications for future use. J Ethnopharmacol 2010; 132: $28-47$ 
45 Moerman DE, Jonas WB. Deconstructing the placebo effect and finding the meaning response. Ann Intern Med 2002; 136: 471-476

46 Blanz M. [Placebos: aspects in medical history and approaches to definition]. Fortschr Neurol Psychiatr 1991; 59: 361-370

47 Howlett AC. Reverse pharmacology applied to the cannabinoid receptor. Trends Pharmacol Sci 1990; 11: 395-397

48 Breinbauer $R$, Vetter IR, Waldmann $H$. From protein domains to drug candidates-natural products as guiding principles in the design and synthesis of compound libraries. Angew Chem Int Ed Engl 2002; 41: 2879-2890

49 Cragg GM, Newman DJ, Snader KM. Natural products in drug discovery and development. J Nat Prod 1997; 60: 52-60

50 La Clair JJ. Natural product mode of action (MOA) studies: a link between natural and synthetic worlds. Nat Prod Rep 2010; 27: 969-995

51 Thornburg CC, Zabriskie TM, McPhail KL. Deep-sea hydrothermal vents: potential hot spots for natural products discovery? J Nat Prod 2010; 73: 489-499

52 Potterat 0 , Hamburger $M$. Drug discovery and development with plantderived compounds. Prog Drug Res 2008; 65: 45-118

53 Etkin NL. Perspectives in ethnopharmacology: forging a closer link between bioscience and traditional empirical knowledge. J Ethnopharmacol 2001; 76: 177-182

54 Adams $M$, Berset $C$, Kessler $M$, Hamburger $M$. Medicinal herbs for the treatment of rheumatic disorders-a survey of European herbals from the 16th and 17th century. J Ethnopharmacol 2009; 121: 343-359

55 Verpoorte R, Crommelin D, Danhof M, Gilissen LJ, Schuitmaker H, van der Greef J, Witkamp RF. Commentary: "A systems view on the future of medicine: inspiration from Chinese medicine?". J Ethnopharmacol 2009; 121: 479-481

56 Sagen AL, Gertsch J, Becker R, Heilmann J, Sticher O. Quinolizidine alkaloids from the curare adjuvant Clathrotropis glaucophylla. Phytochemistry 2002; 61: 975-978

57 Gratus C, Wilson S, Greenfield SM, Damery SL, Warmington SA, Grieve $R$ Steven NM, Routledge P. The use of herbal medicines by people with cancer: a qualitative study. BMC Complement Alternat Med 2009; 9: 14

58 Neldner $\mathrm{KH}$. Complementary and alternative medicine. Dermatol Clin 2000; 18: 189-193

59 World Health Organization. Traditional, complementary and alternative medicines and therapies. Washington DC: WHO Regional Office for the Americas/Pan American Health Organization (Working group OPS/OMS); 1999

60 World Health Organization. Traditional medicine. Available at http:// www.who.int/mediacentre/factsheets/fs134/en/. Accessed January 15, 2010

61 Graziose R, Lila MA, Raskin I. Merging traditional Chinese medicine with modern drug discovery technologies to find novel drugs and functional foods. Curr Drug Discov Technol 2010; 7: 2-12

62 Eng $C$. Are herbal medicines ripe for the cancer clinic? Sci Transl Med 2010; 2 : 45ps41

63 Lam W, Bussom S, Guan F, Jiang Z, Zhang W, Gullen EA, Liu SH, Cheng YC. The four-herb Chinese medicine PHY906 reduces chemotherapy-induced gastrointestinal toxicity. Sci Transl Med 2010; 2: 45-59

64 Melzer J, Brignoli R, Diehm C, Reichling J, Do DD, Saller R. Treating intermittent claudication with Tibetan medicine Padma 28: does it work? Atherosclerosis 2006; 189: 39-46

65 Melzer J, Schrader E, Brattström A, Schellenberg R, Saller R. Fixed herbal drug combination with and without butterbur (Ze 185) for the treatment of patients with somatoform disorders: randomized, placebocontrolled pharmaco-clinical trial. Phytother Res 2009; 23: 1303-1308

66 Rodd R. Snuff synergy: preparation, use and pharmacology of yopo and Banisteriopsis caapi among the Piaroa of southern Venezuela. J Psychoactive Drugs 2002; 34: 273-279

67 Gable RS. Risk assessment of ritual use of oral dimethyltryptamine (DMT) and harmala alkaloids. Addiction 2007; 102: 24-34

68 Nahrstedt A, Butterweck $V$. Lessons learned from herbal medicinal products: the example of St. John's Wort (perpendicular). J Nat Prod 2010; 73: 1015-1021

69 Ulrich-Merzenich G, Panek D, Zeitler H, Vetter H, Wagner H. Drug development from natural products: exploiting synergistic effects. Indian J Exp Biol 2010; 48: 208-219

70 Liu RH. Potential synergy of phytochemicals in cancer prevention: mechanism of action. J Nutr 2004; 134 (Suppl. 12 ): 3479S-3485S
71 Liao ZG, Liang XL, Zhu JY, Zhao GW, Yang M, Wang GF, Jiang QY, Chen XL. Correlation between synergistic action of Radix Angelica dahurica extracts on analgesic effects of Corydalis alkaloid and plasma concentration of dl-THP. J Ethnopharmacol 2010; 129: 115-120

72 Wagner $H$. Synergy research: a new approach to evaluating the efficacy of herbal mono-drug extracts and their combinations. Nat Prod Commun 2009; 4: 303-304

73 Hellmann JK, Münter S, Wink M, Frischknecht F. Synergistic and additive effects of epigallocatechin gallate and digitonin on Plasmodium sporozoite survival and motility. PLoS One 2010; 5: e8682

74 Wang L, Zhou GB, Liu P, Song JH, Liang Y, Yan XJ, Xu F, Wang BS, Mao JH, Shen ZX, Chen SJ, Chen Z. Dissection of mechanisms of Chinese medicinal formula Realgar-Indigo naturalis as an effective treatment for promyelocytic leukemia. Proc Natl Acad Sci USA 2008; 105: 4826-4831

75 Wang Y, Qin Q Chen J, Kuang X, Xia J, Xie B, Wang F, Liang H, Qi Z. Synergistic effects of Isatis tinctoria L. and tacrolimus in the prevention of acute heart rejection in mice. Transpl Immunol 2009; 22: 5-11

76 Shi Q Liu Z, Yang Y, Geng P, Zhu YY, Zhang Q Bai F, Bai G. Identification of anti-asthmatic compounds in Pericarpium citri reticulatae and evaluation of their synergistic effects. Acta Pharmacol Sin 2009; 30: 567-575

77 Lin FM, Chen LR, Lin EH, Ke FC, Chen HY, Tsai MJ, Hsiao PW. Compounds from Wedelia chinensis synergistically suppress androgen activity and growth in prostate cancer cells. Carcinogenesis 2007; 28: 2521-2529

78 Ginsburg I, Sadovnik M, Sallon S, Milo-Goldzweig I, Mechoulam R, Breuer A, Gibbs D, Varani J, Roberts S, Cleator E, Singh N. 47PADMA-28, a traditional Tibetan herbal preparation inhibits the respiratory burst in human neutrophils, the killing of epithelial cells by mixtures of oxidants and pro-inflammatory agonists and peroxidation of lipids. Inflammopharmacology 1999; 7: 47-62

79 Chicca A, Raduner S, Pellati F, Strompen T, Altmann KH, Schoop R, Gertsch $J$. Synergistic immunomopharmacological effects of N-alkylamides in Echinacea purpurea herbal extracts. Int Immunopharmacol 2009; 9: 850-858

80 Hemalswarya S, Doble $M$. Potential synergism of natural products in the treatment of cancer. Phytother Res 2006; 20: 239-249

81 Gathirwa JW, Rukunga GM, Mwitari PG, Mwikwabe NM, Kimani CW, Muthaura CN, Kiboi DM, Nyangacha RM, Omar SA. Traditional herbal antimalarial therapy in Kilifi District, Kenya. J Ethnopharmacol 2011; 134: 434-442

82 Fiebich BL, Knörle R, Appel K, Kammler T, Weiss G. Pharmacological studies in an herbal drug combination of St. John's Wort (Hypericum perforatum) and passion flower (Passiflora incarnata): In vitro and in vivo evidence of synergy between Hypericum and Passiflora in antidepressant pharmacological models. Fitoterapia 2011; 82: 474-480

83 Adams LS, Seeram NP, Hardy ML, Carpenter C, Heber D. Analysis of the interactions of botanical extract combinations against the viability of prostate cancer cell lines. Evid Based Complement Alternat Med 2006; 3: 117-124

84 Berenbaum MC. What is synergy? Pharmacol Rev 1989; 41: 93-141

85 Hastings $I$. How artemisinin-containing combination therapies slow the spread of antimalarial drug resistance. Trends Parasitol 2011; 27: 67-72

86 Gatti A, Sabato E, Di Paolo AR, Mammucari M, Sabato AF. Oxycodone/ paracetamol: a low-dose synergic combination useful in different types of pain. Clin Drug Investig 2010; 30: 3-14

87 MacPherson RD. The pharmacological basis of contemporary pain management. Pharmacol Ther 2000; 88: 163-185

88 Bansal T, Akhtar N, Jaggi M, Khar RK, Talegaonkar S. Novel formulation approaches for optimising delivery of anticancer drugs based on P-glycoprotein modulation. Drug Discov Today 2009; 14: 1067-1074

89 Bebrone C, Lassaux P, Vercheval L, Sohier JS, Jehaes A, Sauvage E, Galleni $M$. Current challenges in antimicrobial chemotherapy: focus on betalactamase inhibition. Drugs 2010; 70: 651-679

90 Atal CK, Zutshi U, Rao PG. Scientific evidence on the role of Ayurvedic herbals on bioavailability of drugs. J Ethnopharmacol 1981; 4: 229-232

91 Efferth T, Koch E. Complex interactions between phytochemicals. The multi-target therapeutic concept of phytotherapy. Curr Drug Targets 2011; 12: 122-132

92 Wang SP, Liu L, Wang LL, Jiang P, Zhang JQ Zhang WD, Liu RH. Screening and analysis of the multiple absorbed bioactive components and metabolites in rat plasma after oral administration of Jitai tablets by high-performance liquid chromatography/diode-array detection coupled with electrospray ionization tandem mass spectrometry. Rapid Commun Mass Spectrom 2010; 24: 1641-1652 
93 Atal CK, Dubey RK, Singh J. Biochemical basis of enhanced drug bioavailability by piperine: evidence that piperine is a potent inhibitor of drug metabolism. J Pharmacol Exp Ther 1985; 232: 258-262

94 Anand P, Thomas SG, Kunnumakkara AB, Sundaram C, Harikumar KB, Sung B, Tharakan ST, Misra K, Priyadarsini IK, Rajasekharan KN, Aggarwal BB. Biological activities of curcumin and its analogues (Congeners) made by man and Mother Nature. Biochem Pharmacol 2008; 76: 1590-1611

$95 \mathrm{Hu} \mathrm{G}$, Baker SP. Trends in unintentional injury deaths, U.S., 19992005: age, gender, and racial/ethnic differences. Am J Prev Med 2009; 37: 188-194

96 Colalto $C$. Herbal interactions on absorption of drugs: Mechanisms of action and clinical risk assessment. Pharmacol Res 2010; 62: 207-227

97 Madabushi R, Frank B, Drewelow B, Derendorf H, Butterweck V. Hyperforin in St. John's wort drug interactions. Eur J Clin Pharmacol 2006; 62: 225-233

98 Zhou SF, Xue CC, Yu XQ Wang G. Metabolic activation of herbal and dietary constituents and its clinical and toxicological implications: an update. Curr Drug Metab 2007; 8: 526-553

99 Zeng ZP, Jiang JG. Analysis of the adverse reactions induced by natural product-derived drugs. Br J Pharmacol 2010; 159: 1374-1391

100 Roeder $E$, Wiedenfeld $H$. Pyrrolizidine alkaloids in medicinal plants of Mongolia, Nepal and Tibet. Pharmazie 2009; 64: 699-716

101 Heinrich M, Chan J, Wanke S, Neinhuis C, Simmonds MS. Local uses of Aristolochia species and content of nephrotoxic aristolochic acid 1 and 2-a global assessment based on bibliographic sources. J Ethnopharmacol 2009; 125: 108-144

102 Berenbaum MC. Synergy assessment with growth curves. J Infect Dis 1984; 150: 304

103 Berenbaum MC. Minor synergy and antagonism may be clinically important. J Antimicrob Chemother 1987; 19: 271-273

104 Leão PN, Pereira AR, Liu WT, Ng J, Pevzner PA, Dorrestein PC, König GM, Vasconcelos VM, Gerwick WH. Synergistic allelochemicals from a freshwater cyanobacterium. Proc Natl Acad Sci USA 2010; 107: 11183-11188

105 Shiojiri K, Ozawa R, Kugimiya S, Uefune M, van Wijk M, Sabelis MW, Takabayashi J. Herbivore-specific, density-dependent induction of plant volatiles: honest or "cry wolf" signals? PLoS One 2010; 5: e12161

106 Kessler A, Baldwin IT. Defensive function of herbivore-induced plant volatile emissions in nature. Science $2001 ; 291$ : 2141-2144

107 Gertsch J, Tobler RT, Brun R, Sticher O, Heilmann J. Antifungal, antiprotozoal, cytotoxic and piscicidal properties of Justicidin B and a new arylnaphthalide lignan from Phyllanthus piscatorum. Planta Med 2003; 69: 420-424

108 Corning PA. The synergism hypothesis: on the concept of synergy and it's role in the evolution of complex systems. J Soc Evol Syst 1998; 21: 133-172

109 McLean S, Duncan AJ. Pharmacological perspectives on the detoxification of plant secondary metabolites: implications for ingestive behavior of herbivores. J Chem Ecol 2006; 32: 1213-1228

110 Yang CS, Lambert JD, Sang S. Antioxidative and anti-carcinogenic activities of tea polyphenols. Arch Toxicol 2009; 83: 11-21

111 Zhang HY, Chen LL, Li XJ, Zhang J. Evolutionary inspirations for drug discovery. Trends Pharmacol Sci 2010; 31: 443-448

112 Firn RD, Jones CG. A Darwinian view of metabolism: molecular properties determine fitness. J Exp Bot 2009; 60: 719-726

113 Firn RD, Jones CG. Natural products-a simple model to explain chemical diversity. Nat Prod Rep 2003; 20: 382-391

114 Ewers RM, Thorpe S, Didham RK. Synergistic interactions between edge and area effects in a heavily fragmented landscape. Ecology 2007; 88: 96-106

115 Schoenian I, Spiteller M, Ghaste M, Wirth R, Herz H, Spiteller D. Chemical basis of the synergism and antagonism in microbial communities in the nests of leaf-cutting ants. Proc Natl Acad Sci USA, in press

$116 \mathrm{Hu}$ Y, Platzer EG, Bellier A, Aroian RV. Discovery of a highly synergistic anthelmintic combination that shows mutual hypersusceptibility. Proc Natl Acad Sci USA 2010; 107: 5955-5960

117 Firn RD, Jones CG. The evolution of secondary metabolism - a unifying model. Mol Microbiol 2000; 37: 989-994

118 Cordell GA, Colvard MD. Some thoughts on the future of ethnopharmacology. J Ethnopharmacol 2005; 100: 5-14

119 de Sá Alves FR, Barreiro EJ, Fraga CA. From nature to drug discovery: the indole scaffold as a "privileged structure". Mini Rev Med Chem 2009; 9: 782-793
120 Fischbach MA, Clardy J. One pathway, many products. Nat Chem Biol 2007; 3: 353-355

121 Fischbach MA, Walsh CT, Clardy J. The evolution of gene collectives: How natural selection drives chemical innovation. Proc Natl Acad Sci USA 2008; 105: 4601-4608

122 Gertsch J, Leonti M, Raduner S, Racz I, Chen JZ, Xie XQ, Altmann KH, Karsak M, Zimmer A. Beta-caryophyllene is a dietary cannabinoid. Proc Natl Acad Sci USA 2008; 105: 9099-9104

123 Moussaieff A, Mechoulam R. Boswellia resin: from religious ceremonies to medical uses; a review of in vitro, in vivo and clinical trials. J Pharm Pharmacol 2009; 61: 1281-1293

124 Perry N, Perry E. Aromatherapy in the management of psychiatric disorders: clinical and neuropharmacological perspectives. CNS Drugs 2006; 20: 257-280

125 Romics I, Siller G, Kohnen R, Mavrogenis S, Varga J, Holman E. A special terpene combination (Rowatinex ${ }^{\circledR}$ ) improves stone clearance after extracorporeal shockwave lithotripsy in urolithiasis patients: results of a placebo-controlled randomised controlled trial. Urol Int, in press

126 Kohlert C, van Rensen I, März R, Schindler G, Graefe EU, Veit M. Bioavailability and pharmacokinetics of natural volatile terpenes in animals and humans. Planta Med 2000; 66: 495-505

127 Buckle J. Use of aromatherapy as a complementary treatment for chronic pain. Alternat Ther Health Med 1999; 5: 42-51

128 Wink M. Evolution of secondary metabolites from an ecological and molecular phylogenetic perspective. Phytochemistry 2003; 64: 3-19

129 McFrederick QS, Fuentes JD, Roulston T, Kathilankal JC, Lerdau M. Effects of air pollution on biogenic volatiles and ecological interactions. Oecologia 2009; 160: 411-420

130 Busch B, Hertweck C. Evolution of metabolic diversity in polyketidederived pyrones: using the non-colinear aureothin assembly line as a model system. Phytochemistry 2009; 70: 1833-1840

131 Bode HB, Bethe $B$, Höfs $R$, Zeeck A. Big effects from small changes: possible ways to explore nature's chemical diversity. Chembiochem 2002; 3: 619-627

132 Williamson EM. Synergy and other interactions in phytomedicines Phytomedicine 2001; 8: 401-409

133 Ulrich-Merzenich G, Panek D, Zeitler H, Wagner $H$, Vetter $H$. New perspectives for synergy research with the "omic"-technologies. Phytomedicine 2009; 16: 495-508

134 Tong AHY, Evangelista M, Parsons AB, Xu H, Bader GD, Pagé N, Robinson $M$, Raghibizadeh S, Hogue CWV, Bussey H, Andrews B, Tyers M, Boone C. Systematic genetic analysis with ordered arrays of yeast deletion mutants. Science 2001; 294: 2364-2368

135 Yeh P, Tschumi AI, Kishony R. Functional classification of drugs by properties of their pairwise interactions. Nat Genet 2006; 38: 489-494

136 Gertsch J, Viveros-Paredes JM, Taylor P. Plant immunostimulants-Scientific paradigm or myth? J Ethnopharmacol, advance online publication July 8 2010; doi: 10.1016/j.jep.2010.06.044

137 Ríos JL, Recio MC, Escandell JM, Andújar I. Inhibition of transcription factors by plant-derived compounds and their implications in inflammation and cancer. Curr Pharm Des 2009; 15: 1212-1237

138 Yeh P, Kishony R. Networks from drug-drug surfaces. Mol Syst Biol 2007; $3: 85$

139 Fitzgerald JB, Schoeberl B, Nielsen UB, Sorger PK. Systems biology and combination therapy in the quest for clinical efficacy. Nat Chem Biol 2006; 2 : 458-466

140 Lehár J, Krueger AS, Avery W, Heilbut AM, Johansen LM, Price ER, Rickles RJ, Short 3rd GF, Staunton JE, Jin X, Lee MS, Zimmermann GR, Borisy AA Synergistic drug combinations tend to improve therapeutically relevant selectivity. Nat Biotechnol 2009; 27: 659-666

141 Rollinger JM, Schuster D, Danzl B, Schwaiger S, Markt P, Schmidtke M, Gertsch J, Raduner S, Wolber G, Langer T, Stuppner $H$. In silico target fishing for rationalized ligand discovery exemplified on constituents of Ruta graveolens. Planta Med 2009; 75: 195-204

142 Leonti M, Cabras S, Weckerle CS, Solinas MN, Casu L. The causal dependence of present plant knowledge on herbals - contemporary medicinal plant use in Campania (Italy) compared to Matthioli (1568). J Ethnopharmacol 2010; 130: 379-391

143 Pollio A, De Natale A, Appetiti E, Aliotta G, Touwaide A. Continuity and change in the Mediterranean medical tradition: Ruta spp. (Rutaceae) in Hippocratic medicine and present practices. J Ethnopharmacol 2008; 116: 469-482

144 Minker E, Bartha C, Rózsa Z, Szendrei K, Reisch J. Antispasmogenic effect of rutamarin and arborinine on isolated smooth muscle organs. Planta Med 1979; 37: 156-160 
145 Golub TR. Mining the genome for combination therapies. Nat Med 2003; 9: 510-511

146 Gao JL, He TC, Li YB, Wang YT. A traditional Chinese medicine formulation consisting of Rhizoma Corydalis and Rhizoma Curcumae exerts synergistic anti-tumor activity. Oncol Rep 2009; 22: 1077-1083

147 Gertsch J. How scientific is the science in ethnopharmacology? Historical perspectives and epistemological problems. J Ethnopharmacol 2009; 122: 177-183

148 Woelkart K, Feizlmayr E, Dittrich P, Beubler E, Pinl F, Suter A, Bauer R. Pharmacokinetics of bilobalide, ginkgolide $A$ and $B$ after administration of three different Ginkgo biloba L. preparations in humans. Phytother Res 2010; 24: 445-450

149 Woelkart K, Frye RF, Derendorf H, Bauer R, Butterweck V. Pharmacokinetics and tissue distribution of dodeca-2E,4E,8E,10E/Z-tetraenoic acid isobutylamides after oral administration in rats. Planta Med 2009; 75: $1306-1313$

150 He SM, Li CG, Liu JP, Chan E, Duan W, Zhou SF. Disposition pathways and pharmacokinetics of herbal medicines in humans. Curr Med Chem 2010; 17: 4072-4113

151 Feng C, Liu M, Shi X, Yang W, Kong D, Duan K, Wang Q. Pharmacokinetic properties of paeoniflorin, albiflorin and oxypaeoniflorin after oral gavage of extracts of Radix Paeoniae Rubra and Radix Paeoniae Alba in rats. J Ethnopharmacol 2010; 130: 407-413

152 Butterweck $V$, Liefländer-Wulf $U$, Winterhoff $H$, Nahrstedt A. Plasma levels of hypericin in presence of procyanidin B2 and hyperoside: a pharmacokinetic study in rats. Planta Med 2003; 69: 189-192

153 Xu F, Liu Y, Dong H, Song R, Zhang Z. Pharmacokinetic comparison in rats of six bioactive compounds between Da-Cheng-Qi decoction and its parent herbal medicines. Nat Prod Commun 2010; 5: 795-800

154 Wegener $T$, Wagner $H$. The active components and the pharmacological multi-target principle of STW 5 (Iberogast). Phytomedicine 2006; 13 (Suppl. 5): 20-35

155 Wang X, Wang Z, Sun H, Lv H, Guan H, Meng X, Sun H, Zhang G, Cao H. Pharmacokinetics of cimifugin in rat plasma after oral administration of the extract of Saposhnikovia divaricatae root. Determination of cimifugin by high performance liquid chromatography coupled with solid phase extraction. Arzneimittelforschung 2008; 58: 445-450

156 Lv H, Sun H, Sun W, Liu L, Wang P, Wang X, Cao H. Pharmacokinetic studies of a Chinese triple herbal drug formula. Phytomedicine 2008; 15: $993-1001$

157 Schmid B, Kötter I, Heide L. Pharmacokinetics of salicin after oral administration of a standardised willow bark extract. Eur J Clin Pharmacol 2001; 57: 387-391

158 He SM, Li CG, Liu JP, Chan E, Duan W, Zhou SF. Disposition pathways and pharmacokinetics of herbal medicines in humans. Curr Med Chem, in press
159 López-Moreno CA. Poster 026 "Phytotherapy of malignant and benign tumors with mixtures of extracts of angiosperms from arid zones of North of Mexico". Naples: Natural Products in Cancer Therapy; 2008

160 Schmidt B, Ribnicky DM, Poulev A, Logendra S, Cefalu WT, Raskin I. A natural history of botanical therapeutics. Metabolism 2008; 57: S3S9

161 Kneifel W, Czech E, Kopp B. Microbial contamination of medicinal plants-a review. Planta Med 2002; 68: 5-15

162 Hamburger $M$. New approaches in analyzing the pharmacological properties of herbal extracts. Proc West Pharmacol Soc 2007; 50: 156-161

163 Wolfender JL, Ndjoko K, Hostettmann K. Liquid chromatography with ultraviolet absorbance-mass spectrometric detection and with nuclear magnetic resonance spectroscopy: a powerful combination for the on-line structural investigation of plant metabolites. J Chromatogr A 2003; 1000: 437-455

164 Wang J, van der Heijden R, Spijksma G, Reijmers T, Wang M, Xu G, Hankemeier T, van der Greef J. Alkaloid profiling of the Chinese herbal medicine Fuzi by combination of matrix-assisted laser desorption ionization mass spectrometry with liquid chromatography-mass spectrometry. J Chromatogr A 2009; 1216: 2169-2178

165 Wang J, van der Heijden R, Spruit S, Hankermeier T, Chan K, van der Greef J, Xu G, Wang M. Quality and safety of Chinese herbal medicines guided by a systems biology perspective. J Ethnopharmacol 2009; 126: $31-41$

166 Yu WL, Guizzunti G, Foley TL, Burkart MD, La Clair JJ. An optimized immunoaffinity fluorescent method for natural product target elucidation. J Nat Prod, in press

167 Rosén J, Gottfries J, Muresan S, Backlund A, Oprea TI. Novel chemical space exploration via natural products. J Med Chem 2009; 52: 19531962

168 Jaki BU, Franzblau SG, Chadwick LR, Lankin DC, Zhang F, Wang Y, Pauli GF. Purity-activity relationships of natural products: the case of antiTB active ursolic acid. J Nat Prod 2008; 71: 1742-1748

169 Vornholt W, Hartmann M, Keusgen M. SPR studies of carbohydrate-lectin interactions as useful tool for screening on lectin sources. Biosens Bioelectron 2007; 22: 2983-2988

170 Miyazaki I, Simizu S, Osada H. The application of the chemical array for biological study. Methods Mol Biol 2010; 669: 95-107

171 van Breemen RB, Li Y. Caco-2 cell permeability assays to measure drug absorption. Expert Opin Drug Metab Toxicol 2005; 1: 175-185

172 Bohlin L, Göransson U, Alsmark C, Wedén C, Backlund A. Natural products in modern life science. Phytochem Rev 2010; 9: 279-301

173 Larkins N, Wynn S. Pharmacognosy: phytomedicines and their mechanisms. Vet Clin North Am Small Anim Pract 2004; 34: 291-327 